\title{
Open Innovation Prizes and Challenges: Learnings from the ImagineNation Series
}

\author{
Jennifer Zelmer, Fraser Ratchford and Justin Noble
}

\section{Introduction}

Innovation - defined by the Council of Canadian Academies (2009) as "new or better ways of doing valued things" - is central to the future of healthcare. Although it is relatively easy to identify goals that matter to citizens, clinicians and health systems, the best means to achieve these goals at scale is often less clear, and there may be significant lags between new discoveries or identification of best practices and their widespread adoption (Advisory Panel on Healthcare Innovation 2015; World Health Organization 2005).

The public interest in closing these gaps is high, but accelerating the process is not straightforward. Recent Canadian reviews point to a variety of potential solutions. For example, the Ontario Health Innovation Council advocated for a dedicated innovation office, brokers to connect innovators with resources, investment in local technologies, changes to procurement, creation of incentives and removal of barriers and optimization of pathways to adoption and diffusion of innovations (Ontario Health Innovation Council 2014). Likewise, the Advisory Panel on Healthcare Innovation (2015) made a series of proposals for accelerating progress on a pan-Canadian basis. The findings of these and other reviews strongly suggest the need for innovative thinking and approaches, not just with respect to healthcare delivery and policy, but also with regards to policy and programs that foster innovation in the health sector.

In this context, Canada Health Infoway launched the ImagineNation Challenges in 2011. Like the prize that Charles Lindbergh claimed for the first non-stop flight between New York and Paris or the space industry's XPRIZE, these challenges are based on an open innovation model. Unlike granting or procurement processes that pick who will be supported and may specify the means that will be used, this approach specifies the "what," not the "who" or the "how." Challenge hosts identify a desired outcome and reward innovators who best meet it. In doing so, they can lower participation barriers and engage a broader range of innovators and change agents.

This paper provides an overview of the ImagineNation Challenges experience to date, as well as key lessons learned about what does and does not work to foster participation and progress towards identified goals. We also offer some suggested starting points for those interested in using this approach in other contexts.

\section{ImagineNation Challenges: An Overview}

The ImagineNation Challenges seek to inspire, provoke and promote innovation in health and healthcare to improve the quality of care and the patient experience for Canadians by leveraging widely distributed knowledge, skills and resources to accelerate value from emerging digital solutions. Desired outcomes - such as growth in the use of e-visits or improvement in quality of care through clinical information exchange - are identified up front. Individuals or teams register to participate via a website (<http://www.imaginenationchallenge. $\mathrm{ca} />$ ) and then track their outcomes, share their experiences and receive support through a community of innovators. Teams that are most successful in delivering on the desired outcomes receive recognition, monetary awards and other prizes.

Since 2011, there have been 10 ImagineNation Challenges (Table 1), plus several student/faculty and solution design challenges undertaken separately. They have involved 435 team or individual submissions, 211 volunteer judges, 18 supporting organizations and $\$ 2.3 \mathrm{~m}$ in awards. Collectively, teams' digital health solutions were used almost 75 million times in the course of the challenges, 3.5 million times for consumer-focused solutions and 71.4 million times for solutions designed to be used by clinical teams (Table 1).

Take the 2012-2013 Outcomes Challenge as an example. A diverse range of teams - from one focused on online access to lab results across British Columbia to another expanding systematic reporting of cancer pathology results in Ontario - took part. In some cases, individual organizations participated; in others, teams brought together multiple healthcare providers. For instance, first place in the e-booking category went to a group of regulated health professionals in 14 clinics in British Columbia, including registered massage therapists, chiropractors and their office staff. Second place went to a group of 49 clinics in Quebec. Their focus was to address challenges commonly encountered by patients who need to book last-minute appointments with physicians and by healthcare practitioners and administrators who deal with last-minute appointment cancellations. 
TABLE 1.

Evolution of the ImagineNation Challenges

$\begin{array}{ll}\text { Challenge } & \text { Purpose } \\ \text { Ideas } & \begin{array}{l}\text { Asked Canadians for bold new ideas to transform } \\ \text { healthcare using digital health - how would they enhance } \\ \text { access to services, improve quality of care delivery or } \\ \text { make the system more efficient? }\end{array} \\ \text { Outcomes } & \begin{array}{l}\text { Challenged Canadian healthcare professionals to } \\ \text { accelerate the use and growth of digital health solutions } \\ \text { in their practices or organizations in four areas: } \\ \text { e-booking, patient access to health information, clinical } \\ \text { synoptic reporting and medication reconciliation. }\end{array}\end{array}$

Patient, career and Gathered information on how public investments in digital business impact health have made an impact for patients, on the careers of health professionals, and in helping organizations grow, evolve or better meet the needs of their clients.

Accelerate

Encouraged clinical innovation and consumer health demonstration projects that had received Infoway investment through other programs and successfully met agreed milestones to exceed the original targets and continue to engage new users for their digital health solution.

Public health social Sought to inspire public health organizations in Canada media

e-Connect to use social media initiatives in creative and innovative ways to improve public health.

Challenged healthcare providers to connect digitally with their patients and each other through e-visits, e-requests for prescription renewals and refills, e-requests for services and e-reports on services. The focus was on improving both use and quality of the solutions.

Data impact I and II Invited teams to answer important health and healthcare questions with existing data.

Begun as an experiment, the ImagineNation Challenge series is now a core component of Infoway's innovation program. The challenges have engaged stakeholders at a grassroots level in advancing health and healthcare using digital solutions, including individual Canadians, students, healthcare providers and companies of all sizes. In addition to identifying early adopters and accelerating their progress towards specific outcomes, the goal is to foster a community of innovators for peer support and knowledge exchange, during and beyond the challenge timeframe. One of the ways that this is accomplished is to involve a wide range of national supporting organizations with mutual goals such as safety, quality and improved patient experience. They help to shape challenge questions, recruit participants and judges, share information about challenge teams and outcomes and contribute in other ways. In addition, challenges offer a range of opportunities, such as:

\section{Outcome}

More than 1,000 people participated over the 13-week challenge period: submitting ideas, serving as judges or voting for their favourite suggestions. Videos of award recipients (<https://www.youtube.com/ watch? $v=74 C g \_74 c z \mid A>$ ) showcase the ideas that were brought forward, some of which participants or others went on to develop further.

43 teams from across Canada with a range of solutions took part, from online access to lab test results in $\mathrm{BC}$ to tools to systematically report cancer pathology results in Ontario. Together, they logged more than three million uses of their solutions (mostly by individual consumers), along with an almost $95 \%$ increase in users.

Elicited over 100 patient (<http://imaginenationchallenge.ca/from-burnabyto-halifax-canadians-share-stories-about-health-its-impact-2/>), career (<http://imaginenationchallenge.ca/digital-health-investments-benefitingbusiness-careers-2/>) and business (<http://imaginenationchallenge.ca/ digital-health-investments-benefiting-business-careers-2/>) success stories regarding the use of digital health, which were shared broadly.

Award recipients, the Ottawa Hospital, the Nova Scotia Department of Health and Health PEI, all recorded double-digit growth in the use of their solutions over a six-month period.

29 teams participated in a quest to harness the power of social media to address public health issues and concerns. Together, they achieved over 30 million social media impressions during the course of the challenge.

41 teams participated and together they reached more than 71 million uses of their digital health solutions (mostly related to solutions for clinical teams).

51 submissions from 34 teams furnished new, usable evidence for policy makers, significantly compressing the time it usually takes to undertake such research.

- identifying, celebrating and accelerating early adopters of digital solutions that have strong patient/clinical benefits through a novel open innovation approach;

- fostering a community of innovators for peer support and knowledge exchange, during and beyond the challenge timeframe;

- informing broad-based adoption and investments through case studies, adoption metrics/benchmarks, benefits evaluation and peer support; and

- cost-effective, lower-risk, outcome-oriented investments that encourage participation from a wide range of stakeholders.

Although much of the focus is on the goals of each particular challenge, the intent is also to achieve broader impact through leveraging challenge outcomes. For instance, challenges have 
strengthened Infoway's relationships with supporting organizations and with innovators across Canada. In both cases, this has led to further collaboration and engagement. Likewise, data on use of solutions provided by challenge teams have been used as input to business cases, change management resources and adoption benchmarks for subsequent larger-scale investment. Team experiences have also been shared in a variety of ways and led to subsequent formal evaluations and research. This information helps to inform broad-based adoption and investments through case studies, adoption metrics/benchmarks, benefits evaluation and peer learning. In addition, challenge teams have used their awards to progress their ideas and solutions further. For instance, Niagara Public Health received the Canada's Choice award in the Ideas Challenge and used the prize funds to turn their idea into a mobile app. Infoway too has launched additional investments based on challenge results, both to scale/spread local solutions and to incent broad adoption of proven types of solutions.

\section{Lessons Learned}

As for any innovation, dynamic evolution has been key to the ImagineNation Challenges. This experience has demonstrated that open innovation can be a cost-effective, lower-risk approach to engaging a wide range of stakeholders in advancing desired outcomes. That said, results depend on effective challenge design and implementation. Examples of factors that we have found promote success in the use of this model include:

- Partnerships and outreach: Innovators abound in the health sector, but it is often challenging to reach all those who may be able to contribute to a particular goal. Active involvement of a range of supporting organizations, many of whom leveraged their communications channels to reach key stakeholders, was key. Individual personal outreach also helped to secure participation.

- Active management: Open innovation takes work; successful challenges do not just happen. Good design; effective communication; infrastructure such as a robust online challenge platform; and active engagement of participants, supporting organizations and judges have proven essential.

- Fun: Even grown-ups like to play. Monetary awards matter and help to spark interest in a challenge, but many teams are more motivated by friendly competition and the intrinsic benefits of reaching meaningful goals.

- Nudging: A small amount of external encouragement from something like a challenge - and a crisp and sustained focus on tracking progress towards a specific goal - helps to drive innovation.

- Recognition: Many teams say that the challenges help validate the importance of their work and provide a chance to celebrate successes. Leaders from within and outside participating organizations are also keen to recognize successful teams.

At the same time, we have also learned much about what does not work, such as:

- Complexity: Challenge questions and rules must be streamlined as much as possible. It is easiest for teams to focus and succeed when there is a single clear outcome to pursue.

- Mismatch with issue being addressed: Open innovation works best when there are multiple potential individuals or groups with the skills and capacity to address the goals identified. It needs to be part of a broader portfolio of strategies to support innovation, including addressing underlying enablers and barriers to progress (e.g., capacity-building or policy change).

- Not enough time, or too much: Early recruitment is important. After a certain point, many potential participants feel that they do not have the ability to earn awards or that there is not enough time to qualify. At the same time, judging periods that are too long tend to result in compressed judging just before the deadline when there may be less opportunity for judges to ask questions if needed.

- Incenting speed: The vast majority of challenge submissions come in the last 48 hours prior to the deadline. In the first Data Impact Challenge, we changed the rules so that half of a team's points came from the speed of their submission and half came from its quality. While this had the desired result of encouraging earlier entries, it affected participation in the challenge.

- New challenge too soon: Many individuals, organizations and judges have participated in more than one ImagineNation challenge. A break between opportunities increases participation.

\section{Conclusion}

In a sense, open innovation challenges represent a return to a historical model for incenting innovation, dating back to at least Napoleon's time. In today's digital world, though, there are new ways of connecting teams with each other and with the resources that they need to be successful, of sharing their experiences, of tracking their progress and of celebrating their successes. As the experience of the ImagineNation Challenges illustrates, there are many potential benefits to be had through open innovation, but optimizing results depends on effective challenge design and execution as part of a broader portfolio of strategies to accelerate progress. $\mathrm{HQ}$ 


\section{References}

Advisory Panel on Healthcare Innovation. 2015. Unleashing Innovation: Excellent Healthcare for Canada. Ottawa, ON: Health Canada.

Council of Canadian Academies, Expert Panel on Business Innovation. 2009. Innovation and Business Strategy: Why Canada Falls Short. Ottawa, ON: Council of Canadian Academies.

Ontario Health Innovation Council. 2014. The Catalyst Towards an Ontario Health Innovation Strategy: A Report to the Government of Ontario. Toronto, ON: Author.

World Health Organization. 2005. Bridging the "Know-Do" Gap: Meeting on Knowledge Translation in Global Health. Retrieved March 24, 2016.<www.who.int/kms/WHO_EIP_KMS_2006_2.pdf>.

\section{About the Authors}

Jennifer Zelmer is president of Azimuth Health Group and has an adjunct faculty appointment at the University of Victoria.

Fraser Ratchford is the group program director, Consumer Health and Innovation at Canada Health Infoway. He holds a BMath in computer science from the University of Waterloo and an MHSc in health administration from the University of Toronto.

Justin Noble is program analyst at Canada Health Infoway. He holds a master of public health degree from the University of Waterloo.

\section{Resources for Getting Started with Open Innovation}

The following resources provide useful starting points for those seeking more information about open innovation:

- The US Government's Getting Started with Challenge and Prize Competitions page: <www.digitalgov. gov/2014/03/31/get-started-with-challenge-and-prizecompetitions/>.

- Nesta's Innovation Policy Toolkit: <www.nesta.org.uk/ innovation-policy-toolkit>.

- McKinsey's Using Prizes to Spur Innovation report: $<$ http://www.mckinsey.com/business-functions/strategy-and-corporate-finance/our-insights/using-prizesto-spur-innovation>.

- Deloitte's report on The Craft of Incentive Prize Design: <http://dupress.com/articles/the-craft-ofincentive-prize-design/>.

- ImagineNation Challenge outcomes, rules, judges, awards and more: <www.imaginenationchallenge.ca $>$ (English) or $<$ http://defiimagination.ca/ $>$ (French).

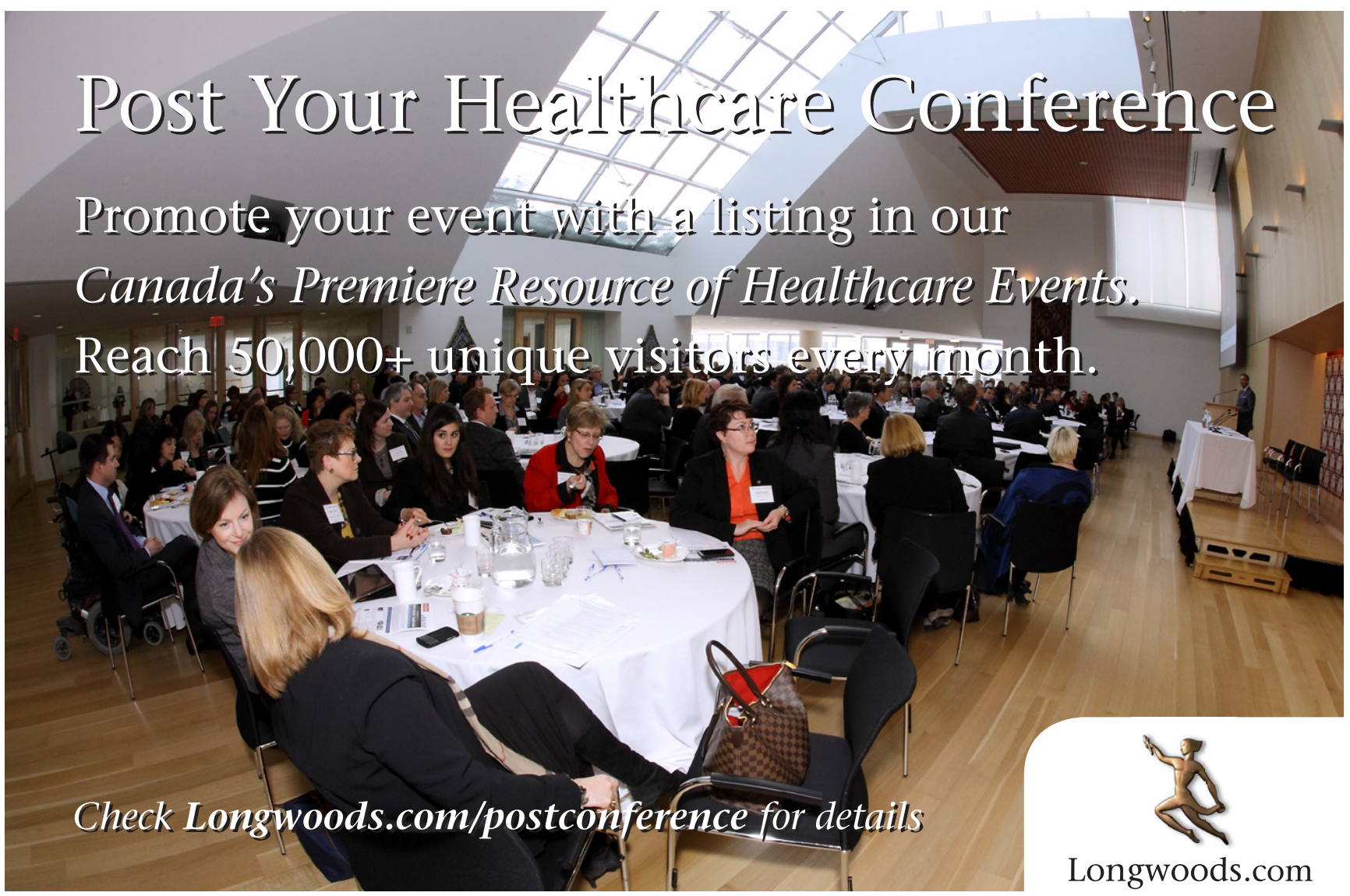

